\title{
DO ENSINO ESCOLAR DA ESCRITA DE TEXTOS NARRATIVOS
}

ON THE SCHOOL TEACHING WRITING OF NARRATIVE TEXTS

Neide Luzia de Rezende*

Universidade de São Paulo, São Paulo, Brasil

Maria Celeste de Souza**

Universidade de São Paulo, São Paulo, Brasil

Resumo: 0 presente artigo expõe o resultado de um exerćíio de reflexão teórica acompanhado de outro, complementar, de aplicaç̃o prática, realizado no curso de Metodologia de Ensino de Língua Portuguesa (MELP) na Faculdade de Educacã̃o da USP, com base ambos baseados na pesquisa que se vem realizando com o objetivo de (re) significar o ensino de escrita de narrativas.

Palavras-chave: ensino; metodologia; língua; escrita; narrativa.

Abstract: This article presents the results of a theoretical reflection upon an exercise by another complementary article of practical application, carried out in the Portuguese Language Teaching Methodology (PLTM) course at the School of Education (Faculdade de Educacaço- USP), based both on research that has been carried out with the objective of (re) signifying the teaching of writing narratives.

Keywords: Teaching; Methodology; Language; Writing; Narrative.

* Universidade de São Paulo - USP, São Paulo, Brasil; Faculdade de Educação; neirez@usp.br

* * Universidade de São Paulo - USP, São Paulo, Brasil; Faculdade de Educação; mcels@usp.br 
Linha D'Água (Online), São Paulo, v. 31, n. 2, p. 143-158, maio-ago. 2018

\section{Introdução}

O presente artigo resulta de um exercício de reflexão teórica acompanhado de outro, complementar, de aplicação prática, ambos baseados na pesquisa que se vem realizando com o objetivo de (re) significar o ensino de escrita de narrativas, atividade corriqueira na educação básica, mas que subsidiada por devidos fundamentos teóricos, particularmente aqueles que a recolocam na condição de um processo privilegiado de construção de conhecimento do mundo, do próprio sujeito produtor de textos e, consequentemente, da linguagem verbal, pode ser de grande valor educativo, além de prazeroso.

\section{Parte 1: Diálogo com as teorias}

A escrita de narrativas é atividade tradicional nos cursos de Língua Portuguesa tanto quanto o estudo da gramática, desde as séries iniciais do ensino fundamental da educação básica no Brasil. A história dessa dupla presença pode ser explicada pela força residual da herança advinda, originalmente, do sistema de educação medieval, responsável por fixar entre os conhecimentos prioritários, a retórica e, com maior importância, a gramática — vista como condição para ler e escrever. ${ }^{1}$

Outro resistente resíduo da tradição vem da ideia de que a aprendizagem se dá por inferências analógicas, o que justifica ensinar primeiro as partes até que se possa chegar ao todo, ou seja: primeiro, as regras gramaticais por meio de conceitos, exemplos e exercícios, até que o estudante possa alcançar domínio da língua

1 Para melhor conhecer essas origens sugere-se a leitura da obra de Ernest Robert Curtius, Literatura Europeia e a Idade Média Latina e nela atentar ao Capítulo III, "Literatura e Educação". Interessa apontar, como informação complementar e muito interessante, a observação do autor sobre o fato de que na Antiguidade não se fazia distinção entre conhecimento de gramática e literatura, visto que, originalmente, o litteratus era "o conhecedor da gramática e da poesia (assim como, na França, o é o lettré), porém não necessariamente um escritor. A palavra literato, hoje tão adulterada, tinha, pois, um significado positivo. $O$ alargamento da noção de gramática leva facilmente a que sejam apagados ou transpostos os limites da retórica, o que já Quintiliano exprobava." (CURTIUS, 1996, p. 78). Tudo indica que o privilégio da gramática afastou gradativamente o texto do centro dos estudos sobre a língua, causa possível de a Literatura vir a se tornar quase uma disciplina à parte, como comumente se verifica nos programas de ensino até nossos dias. 
Linha D'Água (Online), São Paulo, v. 31, n. 2, p. 143-158, maio-ago. 2018

como um todo, preferencialmente aquela com a qual os reconhecidos escritores criam suas obras.

Pode-se afirmar que o peso dessas concepções tradicionais marcou o ensino da língua e ainda hoje, para muitos, é pela gramática que se deve começar, e o conhecimento e estudo desta deve ir das palavras, suas classificações e morfologia, para só mais tarde chegar-se à sintaxe. Sob a mesma lógica, sustenta-se que o aprendizado da escrita deve começar pela elaboração de frases e pequenos textos até que o aluno maduro possa produzir textos integrais. Por sua vez, a escrita de textos de diferentes tipos deve começar pelo aprendizado das partes constitutivas da composição, pelo reconhecimento e classificação dos elementos essenciais da estrutura de cada tipologia textual para, só depois, chegar-se à redação do texto integral, preferencialmente seguindo um modelo ideal.

Claro que esse quadro ilustra um modo de ensinar bastante conservador e quase que totalmente superado. Nas últimas décadas, principalmente, sob a influência das pesquisas e estudos da Linguística, esse modelo tradicional de ensino vem sendo amplamente criticado e alterado com vistas a trazer para o centro do aprendizado as questões relativas à produção de enunciados significativos e à reflexão sobre os usos da linguagem na mais ampla gama de interações sociais. Os próprios PCN, desde 1998, propuseram esse novo olhar para o ensino tradicional.

Entretanto, as mudanças são lentas e ocasionam a convivência de práticas atualizadas com outras conservadoras. Há livros e materiais didáticos em que se verifica o enorme esforço dos autores para tornar concreta a intenção de ensinar a língua a partir de seu funcionamento e uso e há outros materiais e autores que ainda persistem em procedimentos de memorização de regras e conceitos desvinculados da própria natureza dinâmica da linguagem. Importante não esquecer a advertência de Maria Helena de Moura Neves, presente em suas preocupações sobre o ensino de Gramática, ao afirmar

(...) que o tratamento escolar da linguagem tem de fugir da simples proposição de moldes de desempenho (que levam a submissão às normas linguísticas consideradas legítimas) bem como da simples proposição de moldes de organização de entidades metalinguísticas (que levam a submissão estrita a paradigmas considerados modelares). (NEVES, 2015, p. 19) 
No caso da escrita, a influência das concepções bakhtinianas de gêneros discursivos tem revitalizado a reflexão sobre o trabalho com textos. Entretanto, no caso particular do ensino de narrativa, nota-se que a despeito da preocupação com a oferta de um repertório mais amplo de gêneros que vai das lendas, mitos e contos tradicionais até outros mais típicos da novela e do romance como as obras de aventura, a ficção científica, as narrativas fantásticas de mistério e terror, dentre outros, ainda prevalece o ensino de uma matriz estrutural de texto narrativo que varia muito pouco.

É sabido que para além da tradição retórica, o ensino de narrativa está intimamente ligado às teses e teorias advindas dos estudos literários surgidos no século XX, particularmente aos referenciais teóricos do Estruturalismo e às obras de importantes estudiosos como Barthes, Todorov, Genette, Greimas, na corrente francesa e de outros como a búlgara Kristeva, os russos Chklovski, Propp, e estudiosos de língua inglesa como Forster e Frye.

Entretanto, do ponto de vista da significação e da relevância da aprendizagem da produção e da escrita de narrativas, o instrumental de análise e interpretação oferecidos pelos estudos literários não podem responder a várias questões. Não basta aprender a compor textos de acordo com regras claras de estruturação, sem que o processo de criação envolvido, dentre outros fatores, pelas percepções e valores que o autor espera comunicar seja também discutido de modo a se tornar consciência e intencionalidade. Sem isso, a aprendizagem reduz-se a um exercício de fixação de formas e, pior que isso, a elaboração da rica experiência humana que a narrativa sempre representou, desde os povos mais antigos, fica relegada a um plano secundário e o aprendiz, criança ou jovem, perde a oportunidade de conhecer esse percurso tão valioso para a sua constituição de sua identidade.

Tudo indica, portanto, que o ensino de narrativas, particularmente, em termos de escrita precisa ser revisto. A valorização excessiva do aprendizado da morfologia dos elementos de composição do texto acaba por diminuir a importância de outros conhecimentos, muito relevantes, que a produção de textos narrativos pode promover. A título de ilustração, vale destacar que a produção de narrativas pode ser excelente exercício de elaboração da experiência existencial do indivíduo, de uma sociedade e mesmo do mundo; permite ampliar a compreensão do caráter 
provisório de cada estado ou situação da vida, levando ao reconhecimento do caráter transformacional da ação sobre o si mesmo e na realidade. Além disso, é por meio do exercício da elaboração imaginativa que desenhamos sonhos e organizamos o futuro. Tais elaborações são matéria fundamental à compreensão crítica, mais alto objetivo da educação.

Renomada pesquisadora do desenvolvimento do discurso escrito de crianças e jovens, Lucy McCormick Calkins procura em $A$ arte de ensinar a escrever oferecer subsídios ao professor ocupado com o ensino de redação. A paciente descrição do trabalho desenvolvido em oficinas de escrita fez de sua obra uma referência. $\mathrm{O}$ enfrentamento que a autora faz dos problemas relativos ao ensino de escrita resulta em soluções muito interessantes, mas o ensino de escrita de narrativas leva Calkins a reconhecer a necessidade de ampliação de suas pesquisas e reflexões sobre o assunto.

Preocupada com o sentido que a produção e os textos produzidos teriam para as crianças participantes da oficina destinada ao desenvolvimento de narrativas ficcionais, Calkins revela, no último capítulo do seu livro, "Ensinando a ficção e aprendendo o essencial sobre nossa arte", a constatação de que aulas para conhecimento teórico dos elementos estruturais do texto narrativo (personagens, espaço, enredo etc.) são pouco eficazes. Segundo ela, o sentido da produção e o significado do texto não resultam diretamente de conhecimentos sobre a estrutura do texto narrativo, eles dependem de outros fatores que exigem uma abordagem mais complexa.

\begin{abstract}
A boa ficção deve ser sobre algo que importe ao escritor. $O$ texto torna-se trivial, quando pensamos nele como algo uma mentira ou como algo "fabricado". Quero ser clara: não estou dizendo que a ficção deve estar dentro dos limites da experiência real; a sequência de eventos em uma história não precisa jamais ter ocorrido na vida real. A história não precisa contar sobre a cidade natal de alguém, sobre o irmãozinho do escritor ou sobre uma partida de futebol. Mas a própria história deve significar algo, revelar algo que importe. Este significado não vem na forma de um coice moral no final do texto. (CALKINS, 1989, p. 358)
\end{abstract}

Também Tzvetan Todorov, em seu livro Literatura em perigo (2010), discute o ensino de literatura na França, destinado a alunos de nível equivalente ao ensino médio brasileiro, e aponta os perigos de um modelo ocupado prioritariamente com uma abordagem objetal e científica do texto. Dessa perspectiva, a teoria literária e 
Linha D'Água (Online), São Paulo, v. 31, n. 2, p. 143-158, maio-ago. 2018

os procedimentos de análise tornam-se os principais objetos de conhecimento por parte do aluno e não o texto e a obra literária em seu sentido e finalidade amplos, os quais incluem valiosas reflexões sobre a própria humanidade. Segundo ele, os cursos de literatura têm diminuído o espaço das discussões sobre a condição humana e os dilemas existenciais, esforço empreendido pelos escritores de todos os tempos.

Sendo o objeto da literatura a própria condição humana, aquele que a lê e a compreende se tornará não um especialista em análise literária, mas um conhecedor do ser humano. Que melhor introdução à compreensão das paixões e comportamentos humanos do que uma imersão na obra dos grandes escritores que se dedicam a essa tarefa há milênios? E de imediato: que melhor preparação pode haver para todas as profissões baseadas nas relações humanas? Se entendermos assim a literatura e orientarmos dessa maneira seu ensino, que ajuda mais preciosa poderia encontrar o futuro estudante de direito ou de ciências políticas, o futuro assistente social ou psicoterapeuta, o historiador ou o sociólogo? (...). Assim, os estudos literários encontrariam o seu lugar no coração das humanidades, ao lado da história dos eventos e das ideias, todas essas disciplinas fazendo progredir o pensamento e alimentando tanto de obras quanto de doutrinas, tanto de ações políticas quanto de mutações sociais, tanto da vida dos povos da de seus indivíduos. (p. 92-93)

As preocupações de Calkins e de Todorov espelham a inevitabilidade de uma reflexão profunda sobre a finalidade e a significação do ensino de redação de narrativas em âmbito escolar.

Havendo raros estudos sobre o sentido a ser perseguido pelo ensino de narrativa para além de seu lugar ordinário entre outros conhecimentos da língua, temos desenvolvido uma pesquisa que procura situar a discussão na filosofia hermenêutica de Paul Ricoeur. Em sua vasta obra, Ricoeur procurou enfrentar as variadas dimensões da linguagem verbal, marca distintiva do ser humano e de seu modo de construir o mundo. Em um de seus livros, Do texto à ação, Ricoeur discute a relação existente entre as atividades de linguagem, os discursos e os textos, e ações humanas em geral.

O que, no fundo, sempre me interessou mais na análise semiótica ou semântica dos textos, foi o caráter paradigmático da sua configuração no que respeita à sua 
estruturação do campo prático onde os homens figuram como agentes ou como pacientes. É claro que os textos — principalmente os literários — são conjuntos de signos que pouco ou nada romperam as suas ligações com as coisas que eles pressupõem designar. Mas entre as coisas ditas há homens que agem e sofrem; além disso, os próprios discursos são ações; por isso mesmo é que o laço mimético — no sentido mais ativo do termo - entre ato de dizer (e de ler) e o agir efetivo nunca se rompeu completamente. Ele só se tornou mais complexo, mais indireto, pela fissura entre signum e res. (s/d, p. 18)

Pode-se dizer, por tudo isso, que o ensino da escrita e da leitura de narrativas é de grande importância em todas as fases da educação, especialmente porque todo o processo de elaboração desse tipo de texto, se realizado com base em um planejamento que considere o tempo necessário à produção e reflexão sobre ela, poderá contribuir significativamente à elaboração da própria vida prática e interior. A constituição subjetiva realiza-se por meio de inúmeros movimentos de organização das interações com os objetos e os outros. Além disso, a narrativa é uma possibilidade de apreendermos o tempo e sua ação na experiência existencial da humanidade. Ela é um modo de compreensão do caráter dinâmico que não deixa esquecer que o homem é um ser inacabado, um projeto, uma intenção de vir-a-ser que se desenrola na passagem do tempo em meio a peripécias e reviravoltas típicas de uma aventura no desconhecido. Modo de reconhecer, por conseguinte, a moldura das singularidades.

\section{Parte 2: O que dizem os estudantes de MELP sobre o ensino e aprendiza- gem de narrativas?}

Os relatos dos estudantes do curso de Metodologia do Ensino de Língua Portuguesa da FE-USP, no segundo semestre de 2015, confirmaram que o modo como aprenderam a escrever narrativas e aquilo que viam sendo realizado em seus estágios na escola pública eram a supervalorização da estrutura, tratada de forma esquemática e sem uma preocupação real com a significância, tanto do material narrado quanto com a experiência do autor/narrador. Por nossa experiência de ensino, seja no ensino básico como no curso de licenciatura, observamos que as mais 
Linha D'Água (Online), São Paulo, v. 31, n. 2, p. 143-158, maio-ago. 2018

significativas mudanças ocorridas no ensino de narrativas estão relacionadas: 1) à preocupação com a identificação e classificação dos gêneros literários - narrativas de aventura, a fantástica, de suspense, terror, de fiç̧ão científica, do folclórico e lendário etc.; 2) ao uso ainda restrito de recursos tecnológicos como os ambientes virtuais e equipamentos de fotografia e filmagem.

Quanto à estrutura - conhecimento mais valorizado no ensino de narrativa — os elementos estudados são, prioritariamente: tipo de narrador e foco narrativo, tipo de personagem, as modalidades de tempo (cronológico e psicológico), as modalidades espaciais (paisagem e cenário), conflito e desfecho; em termos das estruturas linguísticas: certa preocupação com o uso adequado dos verbos nos tempos do passado e com o uso de advérbios indicativos do tempo e do espaço. Do ponto de vista temático, quase sempre as propostas de redação trazem comandos no sentido de se contar a história de um personagem com características específicas que sirvam a uma abordagem moral; outras vezes, o cenário é o elemento motivador e noutras é a época em que se passa a história.

As estratégias de aula detêm-se na proposição do tema e das condições de produção, bem como na correção pelo professor ou por outro colega e, depois de corrigido o texto, a autor o lê para a sala. O tempo entre uma etapa e outra, em geral, não ultrapassa duas ou quatro aulas de quarenta e cinco minutos cada. Os critérios de avaliação quase sempre tratam da correção gramatical e genericamente da coesão e coerência. Depois de finalizado o texto (quase sempre em uma versão final manuscrita em folha específica ou não) e aprovado pelo professor, ocorre a leitura em voz alta e/ou a publicação em murais na sala de aula.

Uma última observação importante é o fato de que a narrativa em sua estrutura primária, que segue o esquema de sucessão linear (situação inicial - conflito/ clímax - situação final) dos acontecimentos vividos por um ou mais personagens planos e de pouca complexidade, serve de base para o ensino de escrita de narrativas. Os gêneros narrativos que diferenciam as obras literárias (fantástico, aventura, lenda etc.) não são problematizados em relação à extensão e diferenciação estrutural dos textos do romance, da novela e do conto. Assim, pode-se verificar que a narrativa desenvolvida na escola acaba por constituir-se em um gênero particular que se define muito mais pelas condições de produção - tempo de trabalho e 
possiblidade de leitura do professor - do que pelas exigências estruturais do gênero narrativo estudado. Chama atenção o fato de a produção da crônica jornalística ${ }^{2}$, cuja estrutura e linguagem a aproximam do conto, ser ensinada com base nos mesmos elementos estruturais da narrativa tradicional.

Considerando os relatos dos alunos e procurando propor situações práticas em que a produção de textos narrativos alcançasse um nível desejável de significação, propusemos aos alunos de MELP a organização de um plano de aula em que abordassem um aspecto relevante da narrativa, incluindo seus elementos constitutivos. A realização dos planos foi assistida e discutida. O material resultante pode ser exemplificado com os seguintes trabalhos.

\section{Parte 3: Tentativa de renovação das práticas de ensino de escrita de narrativas}

Realizada a apresentação da problemática e das investigações teóricas que fundam a pesquisa em andamento, buscou-se averiguar o que os estudantes, futuros professores, poderiam incorporar em seus planejamentos e práticas de ensino. Pediu-se a eles que, em pequenos grupos, elaborassem planos de aula e preenchessem uma ficha padronizada que buscava organizar as seguintes informações: 1) tema a ser estudado ou objeto de aprendizagem; 2) tópico ou recorte processual a ser abordado na aula; 3) justificativa do objetivo da aprendizagem; 4) organização do tempo da aula: harmonização do espaço da sala, verificação de presença dos alunos e preenchimento de documentos como diários e classe etc., tempo destinado à realização da estratégia didática; 5) descrição detalhada da estratégia didática prevista; 6) listagem dos recursos didáticos requeridos; 6) descrição do tipo de avaliação da aprendizagem e dos critérios de correção e valoração; 7) série/ano a que se destina o trabalho proposto; 8) época do ano (bimestre ou trimestre do ano letivo).

\footnotetext{
2 Usa-se aqui a denominação jornalística apenas para diferenciar o que se convencionou chamar de crônica nos materiais didáticos (tipo de texto híbrido entre o literário e o jornalístico) de outras modalidades de crônica, como a histórica, por exemplo.
} 
Linha D'Água (Online), São Paulo, v. 31, n. 2, p. 143-158, maio-ago. 2018

Dos trabalhos realizados pelos estudantes, selecionaram-se três por dialogarem diretamente com práticas habituais do ensino de escrita. A análise de cada um dos trabalhos será apresentada a seguir:

\section{Grupo $1^{3}$ - Trabalho proposto: reescrita do conto "Chapeuzinho Verme- Iho" por alunos do 6ำ ano do EFII}

Objetivo declarado pelo grupo: 1) que os alunos identificassem o ponto de vista adotado no texto original a partir de elementos de construção do texto, para que desse modo pudessem utilizar esses elementos para construção de uma nova narrativa, desde outro ponto de vista; 2) que percebessem a parcialidade que pode haver nas visões de uma mesma história.

Estratégia definida:1) a leitura em conjunto da conhecida história, Chapeuzinho Vermelho; 2) a discussão dos elementos narrativos que permitem identificar qual o ponto de vista do narrador; 3) organização de grupos e distribuição de diferentes pontos de vista, a partir dos personagens (lobo, vovozinha, caçador). Cada grupo deveria criar uma nova narrativa e, ao final, os alunos deveriam ser capazes de explicitar quais elementos permitem identificar seu narrador. A avaliação principal focalizaria a verificação da coerência da sequência narrativa de acordo com o ponto de vista proposto.

Comentário avaliativo: Trata-se de proposta já conhecida na escola: a de recriar pontos de vista para permitir acesso a novas perspectivas a partir das personagens de uma história. Em geral, a tarefa é realizada de modo mecânico e escolarizado, quase sempre justificada pela falta de tempo para a discussão e aprofundamento. $\mathrm{O}$ texto produzido acaba se reduzindo a falas achatadas e pouco criativas ou adequadas.

Que as crianças sejam capazes de se colocar no lugar das personagens, sem trair a fábula é tarefa complexa, uma vez que a mudança de narrador implica mudança da história, que ganhará novos prismas, o que requer um trabalho minucioso e demorado por parte do professor junto aos alunos. Outra dificuldade é que

3 Composto por três alunas. 
Linha D'Água (Online), São Paulo, v. 31, n. 2, p. 143-158, maio-ago. 2018

crianças, estudantes do $6^{\circ}$ ano, ainda bastante acostumadas à espontaneidade do oral, precisam introjetar o outro: um narrador que descreve, comenta e apresenta cenas e personagens requer um trabalho difícil de reconfiguração do oral para o escrito (VYGOTSKY, 2005, e DOLZ; SCHNEUWLY, 2010), o que significa deixar a relação dialogada em situação de interação presencial para incluir no texto o procedimento linguístico escrito dessa interação; expor o contexto do enunciado é um aprendizado difícil, pela artificialidade da situação. Para tornar mais exequível a tarefa, o professor poderia experimentar propor a troca de narrador em algumas poucas ou em apenas uma das cenas da história, por exemplo, o encontro de Chapeuzinho com o lobo na floresta. ${ }^{4}$

\section{Grupo $2^{5}$ - Trabalho proposto: construir uma história a partir da experiên- cia de vida narrada oralmente por um colega (estudantes do EJA)}

Objetivo declarado pelo grupo: oferecer ao aluno a possibilidade de compreender como os elementos da vida cotidiana podem ser interessantes para compor uma narrativa;

Estratégias: 1) organização dos alunos em duplas; os alunos se sentariam de frente um para o outro para as entrevistas, nas quais teriam acesso a um personagem e a uma história, ou seja, a uma ideia inicial básica com a qual poderiam iniciar a redação; 2) dar orientações sobre como realizar as entrevistas, tendo como base a pergunta: "Qual a sua trajetória escolar até o EJA?"; 3) pedir ao aluno entrevistador para anotar pontos interessantes da fala do colega a fim de que com eles possa, mais tarde, escrever a história; 4) sem dar noções fechadas sobre o modo de construir uma narrativa, pedir que componham em casa um texto contando a história que acabaram de ouvir.

Comentário avaliativo: Esta também é uma atividade conhecida pelos professores. Novamente aqui vamos descamá-la com o intuito de tornar mais profícuo o trabalho. Antes de tudo, convém distinguir dois tipos de textos com potencialidades diferentes: o relato e a narrativa ficcional. Em geral, nos trabalhos escolares, quando

4 Estamos usando a versão do livro dos GRIMM da Cosac \& Naify.

5 Composto por quatro alunas.

REZENDE, N. L.; SOUZA, M. C. Do ensino escolar da escrita de textos narrativos 
Linha D'Água (Online), São Paulo, v. 31, n. 2, p. 143-158, maio-ago. 2018

se pede para escrever uma narrativa é o relato que é produzido, ou seja, uma apresentação de fatos contados linearmente ao longo do tempo, em que existe uma única personagem, o próprio autor, e não se concebe como possibilidade acréscimos ou invenções, os quais sofrem a vigilância e o controle do próprio escritor. $\mathrm{O}$ resultado em geral desses relatos são fatos da vida que mostram o sofrimento, a superação, as alegrias e os problemas familiares, e, não raro, manifestações acerca das crenças religiosas do indivíduo. Diferentemente, na narrativa ficcional, o enredo não necessariamente é fiel à realidade, bem como as personagens podem ser livremente inventadas. Entretanto, pode-se questionar se haverá, de fato, tanta diferença quanto à matéria de ambos os tipos de narrativa: tão real um e tão ficcional o outro.

Essa diferenciação, no caso da autobiografia, mostra-se eficaz. BRUNER e WEISSER (1995) afirmam que "o ato da elaboração da autobiografia constrói o relato de uma vida. A autobiografia, em poucas palavras, transforma a vida em texto, por mais implícito ou explícito que seja.” (p. 149) e que é só pela textualização que podemos conhecer a vida de alguém,“a autodescrição torna-se uma forma importante não apenas de relatar (de maneira seletiva) o passado, mas também de se libertar de modos anteriormente estabelecidos de responder e organizar respostas ao futuro". (p. 149)

Ou seja, a natureza do autorrelato é interpretativa, dá-se sentido a partir do presente aos fatos do passado. Nossa literatura tem exemplos magníficos dessa reinterpretação do passado em textos que não conseguimos classificar muito bem enquanto gênero e que, quando qualificados como contos, portanto ficcionais, trazem sem dúvida elementos que sabemos fazer parte do passado de seu autor. Exemplos: "Conto de escola", de Machado de Assis, Memórias sentimentais de João Miramar, de Oswald de Andrade, Contos novos, de Mário de Andrade, etc. Quando considerados mais próximos da vida real do autor, são classificados como crônicas, mas guardam um quê de invenção, como são os textos de Infância de Graciliano Ramos.

Pensando nessas dimensões teóricas dos gêneros, seria interessante trazer algumas dessas questões para os estudantes de EJA a fim de que pudessem repensar sua trajetória de vida. Quem sabe fornecer elementos para que refletissem sobre os episódios de suas vidas a partir do presente, enriquecendo-os com novas interpretações, uma vez que a tendência dos relatos feitos em sala é dar aos episódios 
Linha D'Água (Online), São Paulo, v. 31, n. 2, p. 143-158, maio-ago. 2018

um sentido já cristalizado, sem de fato refletir sobre eles ou, em outros casos, procede-se a uma interpretação demasiadamente breve, apenas inserida em polos de avaliação positiva ou negativa.

Um recorte nas histórias de vida poderia oferecer a oportunidade de conhecimento de si pela escrita. Em vez de uma acumulação de fatos da vida, propor aos alunos que escolhessem um fato significativo, que fizessem um recorte para trabalhar a partir dele. Primeiro oralmente, para compartilhar as experiências, e depois, levando em conta as questões originadas no grupo, cada estudante escreveria seu texto, tentando incluir reflexões sobre os fatos selecionados da vida. Um bom ponto de partida seria a leitura de trechos de alguns textos confessionais como Quarto de despejo, de Carolina de Jesus, Minha vida de menina, de Helena Morley, etc.

\section{Grupo $3^{6}$ - Trabalho proposto: criação de uma história/mito a partir de um personagem que também personifique alguma característica humana}

Objetivo declarado pelo grupo: que os alunos do $7^{\circ}$ ano se familiarizassem com a maneira pela qual as personagens são apresentadas nos mitos gregos, através da leitura e discussão dos mesmos. Para isso, propunham a leitura e discussão dos mitos de Narciso e de Ícaro em sala de aula.

Estratégias: 1) Desenhar um quadro na lousa com as colunas "Narciso", "Ícaro", e perguntar aos alunos quais as características que eles notaram em cada personagem (tanto físicas quanto psicológicas); 2) Apresentar aspectos formais que constituem esses tipos de personagens e fazer uma ponte com personagens (do repertório do aluno) que também tenham alguma característica marcante; 3) Explicar aos alunos a proposta de "redação": depois de eles terem aprendido o que forma um personagem, teriam de criar um personagem que também personificasse alguma característica humana e criar uma história/mito para ele; 4) No caso de haver dificuldades em pensar em alguma característica por parte dos alunos, o professor levaria impressos ou escreveria na lousa alguns exemplos de características (bondade, pânico, preguiça...); 5) A avaliação seria feita numa aula posterior. Os

6 Composto por quatro alunas. 
Linha D'Água (Online), São Paulo, v. 31, n. 2, p. 143-158, maio-ago. 2018

alunos que se sentissem confortáveis poderiam ler seu mito para a classe e averiguar se os outros adivinhariam qual a característica marcante do seu personagem.

Comentário avaliativo: Proposta bastante complexa para esses jovens, entretanto, se bem planejada e com satisfatório entendimento do significado dos mitos, pode render aulas muito interessantes e profícuas. Em primeiro lugar, ter uma concepção de mito ajuda a objetivar o trabalho e entender melhor o potencial de aprendizagem que os mitos proporcionam.

Como lembra Lukács (2000), em $A$ teoria do romance, o mito é de um tempo em que não havia separação entre o imaginário e a realidade concreta ou entre deuses e homens, aliás, como é ainda hoje entre os povos indígenas, nas lendas; o pensamento abstrato manifesta-se de modo concreto; os mitos cumprem a função de explicar a origem do mundo. Portanto, as figuras míticas são alegóricas, no sentido de que uma imagem sintetiza toda uma história, ou seja, uma alegoria não expõe diretamente, mas mostra por meio de imagens que, mediante desenvolvimento verbal, criam explicações. No entanto, justamente por necessitarem de explicação e interpretação, os mitos podem ter vários significados. A fábula, no caso, é em geral a mesma conhecida por todos (Narciso era um jovem belo que se apaixonou por si mesmo; Ícaro recebeu asas do pai, Dédalo, fixando-as com cera, voou até o sol e com o calor elas se desprenderam), porém, no trajeto da antiguidade para os nossos dias, a maioria dos mitos foi objeto de muitas interpretações, as histórias foram sendo modificadas e adaptadas.

Para a leitura dos alunos, é fácil encontrar o resumo desses mitos na internet (muitos blogs trazem interpretações de acordo com a área do conhecimento; há muitos esotéricos). Nessas interpretações vigoram a ambição, o desejo de poder, sentimentos que para os antigos se associavam à hybris, nomeação do que é excessivo e deve ser punido. Um bom exercício, seria perguntar o que, modernamente, deveria ser punido de acordo com visão dos meninos dessa idade - bullying, racismo...?

\section{Considerações finais}

Nossos comentários procuram mostrar as potencialidades do diálogo entre teoria e prática e como algumas práticas de ensino se automatizam sem que nos demos 
Linha D'Água (Online), São Paulo, v. 31, n. 2, p. 143-158, maio-ago. 2018

conta de que elas perderam o sentido. Por isso mesmo, confirmam-se os objetivos da pesquisa que estamos realizando com vistas a contribuir com uma reflexão norteada por fundamentos teóricos que possam assegurar a importância do ensino da escrita de narrativas não só como uma tarefa rotineira e comum ao programa de Língua Portuguesa na educação básica, mas, principalmente, como um processo de elaboração de várias dimensões que se encontram no diálogo entre a experiência concreta do mundo e a elaboração dessa experiência, das inter-relações estabelecidas com outras pessoas e nos diálogos que advêm delas, bem como no âmbito dos diálogos que aparentemente cada um realiza só consigo mesmo. Muitas são as possibilidades de o professor disposto a repensar o óbvio encontrar soluções, muitas vezes simples, de promover uma aprendizagem significativa. Essa é a intenção do nosso trabalho.

\section{Referências}

BARTHES, R. E. A. Análise estrutural da narrativa. Petrópolis: Vozes, 2009.

BRUNER, J. e WEISSER, S. A invenção do ser: a autobiografia e suas formas. In: OLSON, David R. e TORRANCE, N. Cultura escrita e oralidade. São Paulo: Ática, 1995.

CALKINS, L. M. A arte de ensinar a escrever. Porto Alegre: Artes Médicas, 1989.

CORTÁZAR, J. Alguns aspectos do conto. In: Valise de Cronópio. São Paulo: Perspectiva, 1974. p. 147-164.

CURTIUS, E.R. Literatura europeia e Idade Média. São Paulo: Hucitec: Edusp, 1996.

DOLZ,J.; SCHNEUWLY, B. et al. Gêneros orais e escritos na escola. Tradução de Roxane Rojo e Glaís Sales Cordeiro. Campinas: Mercado de Letras, 2004.

GRIMM, Jacob e Wilhelm. Contos maravilhosos infantis e domésticos (1812-1815). Ilustrações J. Borges. Trad. Christine Röhrig. Apres. Marcus Mazzari. São Paulo: Cosac Naify, 2012. Chapeuzinho vermelho. T. 1, p. 137-40. 
Linha D'Água (Online), São Paulo, v. 31, n. 2, p. 143-158, maio-ago. 2018

LUKÁCS, Georg. A teoria do romance. Tradução de José Marcos Mariani de Macedo. São Paulo: Duas Cidades; Editora 34, 2000.

NEVES, M.H.M.N. Que gramática estudar na escola? Norma e uso na Língua Portuguesa. São Paulo: Contexto, 2015.

REIS, C. E. L. A. C. M. Dicionário de narratologia. Coimbra: Almedina, 2011.

RICOEUR, P. Da metafísica à moral. Lisboa: Instituo Piaget, 1995.

RICOEUR, P. Tempo e Narrativa. São Paulo: WMF Martins Fontes, v. 1, 2 e 3, 2010.

RICOEUR, P. Leituras 2 - A região dos filósofos. 1996: Loyola.

RICOEUR, P. Do texto à ação: ensaios de hermenêutica II. Lisboa: Rés, s/d.

SOARES, M. Letramento: um tema em três gêneros. Belo Horizonte: Autêntica, 1998.

SPOLIN, Viola. Jogos teatrais. O fichário de Viola Spolin. Tradução de Ingrid Dormien Koudela. São Paulo: Perspectiva, 2014.

TODOROV, T. A literatura em perigo. Rio de Janeiro: Difel, 2010.

VIGOTSKI. L.S. Pensamento e linguagem. São Paulo: Martins Fontes, 2005.

\section{Documentos oficiais}

Ministério da Educação. Lei de Diretrizes e Bases da Educação Nacional - 9394 de 1996.

Ministério da Educação. Parâmetros Curriculares Nacionais - Ensino Médio. 1999.

Ministério da Educação. Parâmetros Curriculares Nacionais - $3^{\circ}$ e $4^{\circ}$ ciclos. 1999.

Recebido: 3/4/2018. Aprovado: 13/09/2018.

REZENDE, N. L.; SOUZA, M. C. Do ensino escolar da escrita de textos narrativos 